
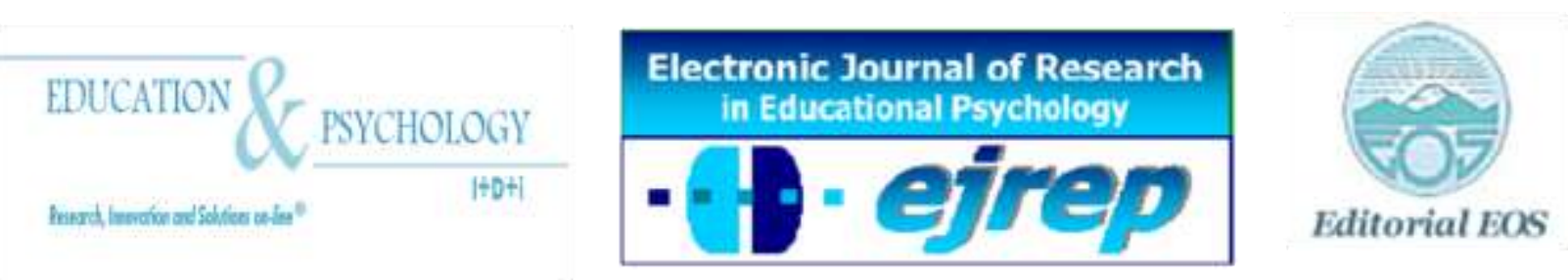

\title{
Are fourth and fifth grade children better scientists through metacognitive learning?
}

\section{Peter Dejonckheere, Kristof Van de Keere, Isabel Tallir}

\author{
Teaching Department PHO, University College of Katho, \\ Tielt
}

\section{Belgium}

Correspondence: Peter Dejonckheere. Katho PHO, Beernegemstraat 10, 8700 B-Tielt. Belgium. E-mail:_peter.dejonckheere@katho.be

(C) Education \& Psychology I+D+i and Editorial EOS (Spain) 


\begin{abstract}
Introduction. A way to find out how scientific thinking in children develops is to focus on the processes that are involved. As such, scientific thinking can be seen as a particular form of problem solving in which the problem solver selects a strategy from the space of possible experiments that can reveal the cause of an event. Notwithstanding the acquisition of such a skill may be a strong constraint on search in the space of experiments, it was questioned whether children's problem solving could be supported by metacognitive instructions.
\end{abstract}

Method. With the aid of a quasi-experimental study it was investigated whether children of 9 and 11 years old were able to design a scientific experiment with material available to them after they were taught how to control the variables in the experiment. A first group of 45 children was taught the technique together with metacognitive support (a step-by-step plan). A second group did so whithout metacognitive support. Finally, a third group received no specific intstructions.

Results. Results with 11-year-olds showed that children who were taught to design a scientific experiment together with metacognitive support outperformed those who didn't receive such instructions. In addition, children who received metacognitive support showed longer problem solving times indicating that their impulsiveness was inhibited. No significant differences were found with children of 9 years old.

Discussion and Conclusion. Children should be encouraged to use metacognitive support in classrooms so that awareness on the level of their thoughts and actions leads to better scientific problem solving.

Keywords: Scientific reasoning, problem solving, primary science, impulsiviness 


\section{¿Son mejores científicos los alumnos de cuarto y quinto de Primaria a través del aprendizaje metacognitivo?}

\section{Resumen}

Introducción. Una de las maneras de saber qué piensan los científicos sobre el desarrollo infantil es enfocarse en los procesos en los que están ocupados. De esta manera, el pensamiento científico se puede ver como una forma particular de resolver problemas, en la cual el encargado de resolverlo selecciona una estrategia dentro la gama de posibles experimentos que puedan revelar la causa de un evento. No obstante, la adquisición de una técnica de este tipo puede ser una fuerte limitación en la búsqueda dentro de la gama de experimentos; se ha cuestionado si la solución de problemas por los niños puede verse favorecida por instrucciones metacognitivas.

Método. Con la ayuda de un estudio cuasi-experimental, se investigó si los niños de 9 y 11 años eran capaces de diseñar un experimento científico con el material que se les había puesto a disposición, después de haberles enseñado como controlar las variables en el experimento. Al primer grupo de 45 niños se les enseñó la técnica junto con el apoyo metacognitivo (un plan paso por paso). Al segundo grupo se le enseñó lo mismo, sin el apoyo metacognitivo. Finalmente, el tercer grupo no recibió instrucciones específicas.

Resultados. Los resultados con niños de 11 años, mostraron que los niños a los cuales se les había enseñado a diseñar un experimento científico junto con el apoyo metacognitivo sobrepasaron aquellos de los que no recibieron estas instrucciones. Por otra parte, los niños que recibieron apoyo metacognitivo se demoraron más tiempo en resolver el problema, lo que indica que su impulsividad se vio inhibida. No se encontraron diferencias significativas con los niños de 9 años.

Discusión y Conclusión. Se deberá estimular a los niños a usar apoyo metacognitivo en las salas de clase, para que la consciencia, a nivel de sus pensamientos y acciones, conduzcan a una mejor solución de problemas científicos.

Palabras clave: Razonamiento científico, solución de problemas, ciencias primarias, impulsividad 


\section{Introduction}

Over the last few decades, there is an increased amount of interest in scientific thinking in pre- and primary schools. Indeed, researchers argued that scientific activities must be organized already in young children to preserve or to strengthen a child's positive attitude towards science and to establish a better understanding of scientific conceps that are studied later in a more formal way (e.g., Eshach and Fried, 2005).

Some authors argue that the development of scientific thinking is merely a consequence of a child's growing knowledge base (e.g., Carey, 1985; Thurston, Grant, \& Topping, 2006). For instance, compared to toddlers, adults show a more extended domainspecific knowledge base such as knowledge of physics, biology, astronomy, geology, etc. Other authors such as Inhelder and Piaget (1958) argue that a child's knowledge base is not a primary source to investigate scientific thinking in childeren. From this view scientific thinking rather emerges from a connection of particular representations, that are qualitatively different by age, about the world and strategies for reasoning about it. Yet another way to study scientific thinking and its development is to focus on the processes that are involved. As such, scientific thinking can be seen as a form of problem solving in which the problem solver searches in a particular problem space (Newell, \& Simon, 1972). Such a problem space consists of all possible states of a problem and all operations that a problem solver can use to get from one state to another (Holyoak \& Morrison, 2005). Klahr and Dunbar (1988) extended this idea to their dual problem space approach. According to them the dual problem space is a space that contains all possible hypotheses and experimental possibilities a problem solver can consider. Three interdependent processes are then needed in order to search into both spaces. A first process is the hypothesis space searching process. The initial state is some prior knowledge and the goal is to find a hypothesis that can account for that knowledge. A second process is the experiment space search in which the problem solver has to find an experiment that can dicriminates between rival hypotheses and that yields interpreteble outcomes. Finally, there is an evaluation process in which the results of the current experiment are compared with the predictions coming from the hypothesis (Klahr, 2005).

A way to strenghten childrens' searching in the problem space is to offer them a good method to set up an experiment that can reveal the cause of an event. For instance, a child is given following instructions: 'Can you demonstrate through an experiment whether the height 
from which a ball is dropped has an effect on the loudness when it hits a surface? Here, you have a heavy ball and here you have a light one. Further there is a wooden and a metal shelf. You can use all these materials to set up your experiment. How do you start this? (See Figure $1)$.

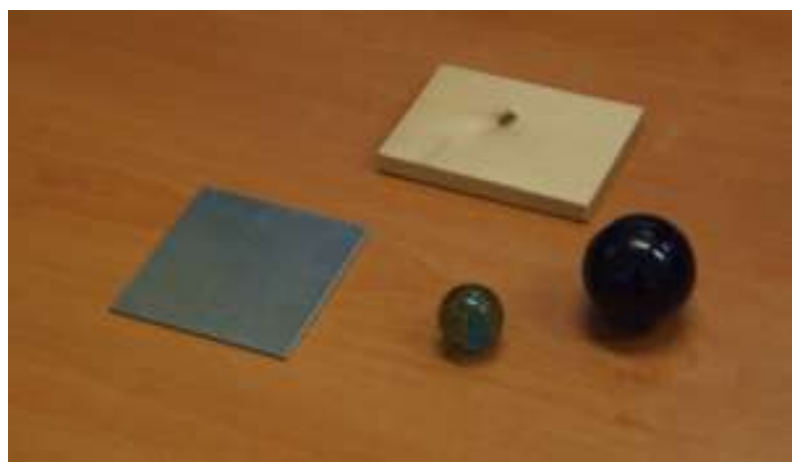

Figure 1. In the post-test, children had to demonstrate through an experiment with the material available to them whether the height of a ball has an effect on the loudness of its fall.

In order to solve this problem, the child can be trained to set up two similar experiments in which one variable at a time is varied (the height of the ball) whereas the others variables are kept constant (in this case: the weight of the ball and the surface material). As long as the child sets up a confounded experiment (more than on variable is varied at a time), the generated evidence is indeterminate and the knowledge not very useful. Such a strategy is called a controlled comparison strategy (CCS) (Chen \& Klahr, 1999; Klahr, 2000; Kuhn, Black, Keselman, \& Kaplan, 2000). The acquisition of such a method can be a hallmark in the development of scientific reasoning since few elementary school children use the method spontaneously. Moreover, it seemed that after instruction, children become better scientific problem solvers. For instance, in a study of Klahr and Nigam (2004) fourth grade children experimented with wooden ramps along which a ball could roll. The childeren were divided in two groups. One group received examples of good and bad experiments. They also were explained how to make a valid inference from a controlled comparison. Another group experimented without any instructor feedback. Then, in a post-test children of both groups were asked to design a set of unconfounded experiments. It was found that only $23 \%$ of the children mastered the scientific method spontaneously whereas $77 \%$ did this after receiving instructions from the teacher. An explanation is that teaching the controlled comparison strategy provided a strong constraint on search in the childrens' experiment space (Chen \& 
Klahr, 1999). This means that the process of scientific problem solving is a lot more accurate when children are able to select an appropriate strategy more precisely.

However, failure in (scientific) problem solving in children is often due to a lack of adequate monitoring, assessing and decision making skills (Teong, 2003). Indeed, metacognition is an important component of learning which refers to higher order thinking skills that encompass an active control over thinking processes that are involved in learning (Desoete, 2007; Hofstein, Kipnis, \& Kind, 2008). According to Flavell (1976) metacognition includes knowledge about person variables (knowledge about one's self, and others' thinking), task variables (knowledge that different types of tasks exert different types of cognitive demands) and strategy variables (knowledge about cognitive and metacognitive strategies for enhancing learning and performance) on the one hand and cognitive regulation on the other. Metacognitive regulation and metacognitive strategies are processes that are used to control cognitive activities in order to achieve a pre-set goal. They help to regulate and oversee learning, and consist of planning and monitoring cognitive activities, as well as checking the outcomes of those activities (Livingston, 1996) and have been associated with intelligence (e.g., Borkowski, Carr, \& Pressley, 1987). Metacognition is already an important issue in memory development and reading since it highlighted how readers plan, monitor, and control their own text comprehension (e.g, Palincsar \& Brown, 1984; Pearson \& Dole, 1987; Pearson \& Fielding, 1991; Pressley, Johnson, Symons, McGoldrick, \& Kurita, 1989). Palincsar and Brown (1984), for instance, used a number of comprehension strategies (prediction, questioning, seeking clarification when confused and summarization) combined with reciprocal teaching with grade-7 students who had problems with reading comprehension. It was found that deeper comprehension was obtained after the metacognitive intervention. The authors observed more correct processing, better summarization skills, more question-generation competencies and better monitoring (Pressley, 1998).

Within the scientific thinking domain, research has repeatedly demonstrated that metacognitive support improves performance (Beishuizen, Wilhelm, \& Schimmel, 2004; Lan \& Repman, 1998; White \& Frederiksen, 1998; Wilhelm, Beishuizen, \& Van Rijn, 2005; Zion, Michalsky, \& Mevarech, 2005). For instance, White and Frederiksen (1998) investigated whether students from grades 7 and 9 benefitted from learning the inquiry cycle. Following this cycle, students persued a sequence of research goals in which they first formulated a question and then generated a set of hypotheses related to that question. Then they effectively 
executed the experiments, analyzed the data and applied their findings to various situations. Finally, students reflected on the outcome. Results showed that students who received the instructional program showed more insight in a number of phycical laws and they showed more interest in the field of physics in general.

In Dejonckheere, Van de Keere, and Mestdagh (2010) the effects of metacognitive support for physical reasoning in elementary school children were studied. In one of their experiments, children of 6,7 and 9 years old were asked to build a raft that could carry a metal object (6-and 7-year-olds) or to light one or more lamps in an electrical circuit (9-yearolds). However, before doing this, one group received metacognitive support for $2 \times 50 \mathrm{~min}$ at three different points in time with a 3-week break between. In contrast, controls continued with their normal courses. Metacognitive support consisted of learning the scientific thinking circle analogous to the inquiry cycle of White and Frederiksen (1998) but now adapted to elementary school children. In the scientific thinking circle children were first encouraged to phrase the problem in their own words starting from a particular problem. For instance, they were asked to build a bridge that could carry a car using the material available to them. Secondly, children had to formulate a number of proposals to solve the problem. So, they were forced to engage in thought experiments which builds the representation of the question and task goals. Thirdly, children executed the problem and finally, results were evaluated. Each step of the thinking process was represented by a bear (Bash \& Camp, 1975) that aimed to strenghten the mental representations while solving the problem. Results showed that this metacognitive support gave rise to better problem solving in a post-test: children displayed more operations that were in accordance with physical laws and fewer operations that violated these physical laws. For instance when children had to build a raft that could carry a metal object it was observed that they were less inclined to put a metal object directly into the water (noncompatible operation), and that they more frequently used floating beams in order to support the raft (compatible operation). The results of the study also revealed that children who received metacognitive support spent more time completing some aspects of a post-test. This can be considered as an inhibition of impulsive behaviour (Dejonckheere, Van de Keere, \& Mestdagh, 2010; Kamann \& Wong, 1993; Meichenbaum, 1990). It is generally observed that experts in a specific (scientific) domain spend proportionately more time than do novices. The increased use of time can be due to a better organization, elaboration, planning, monitoring and regulation of its (cognitive) activities (Reynolds \& Miller, 2003). As such the total time spent can be considered as a measure of metacognitive learning. 
In the present study children are taught a controlled comparison strategy (CCS) similar as used by Chen and Klahr (1999) in order to constrain the search in the space of experiments. Teaching the strategy will occur with and without metacognitive instructions. The folowing research questions can be put forward:

1) Is there an effect of learning the controlled comparison strategy (CCS) on scientific problem solving?

2) Is there an effect of metacognitive support on scientific problem solving while training CCS?

\section{EXPERIMENT 1}

\section{Method}

\section{Participants}

The sample existed of 45 children (19 boys and 26 girls) of 9 years old (they ranged in age from 9 years 5 months to 10 years 3 months). Participants camed from three different classes from three different schools in the West-Flanders and East-Flanders region in Belgium serving a middle income population. A class was assigned to either the CCS+MS-group (controlled comparison strategy + metacognitive support; 15 children), the CCS-group (controlled comparison strategy; 15 children) or the C-group (controls; 15 children). Participants were not identified as at risk neither did they perform below grade level. They were all of West European ethnicity. Parents were asked to sign an agreement for participation of their child. Children nor their parents were rewarded for their participation.

\section{Design and Procedure}

Nine-year-old children were taught how to design a scientific experiment. Choosing this age group is in line with other studies that found significant effects of teaching scientific strategies such as Chen and Klahr (1999) and Klahr and Nigam (2004). We compared two teaching methods supporting children's scientific problem solving. In a first teaching method children were explained how to solve a scientific problem with the aid of the controlled comparison strategy in order to provide a strong constraint on search in the experiment space. In 
the second teaching method children received the controlled comparison strategy too but they additionally received metacognitive support through the scientific thinking circle as used by Dejonckheere, Van de Keere and Mestdagh (2010). A third group didn't receive any instructions. Then, in a post-test it was examined to which extent the 9-year-olds were able to design two simple unconfounded experiments with material available to them after they were presented two scientific questions. In addition, it was measured how much time children needed to solve these scientific questions.

Experiment 1 consisted of 3 different phases. A pre-test phase, an instruction phase and a post-test phase. Two final year female student teachers from the University College of Katho (PHO) were involved in this experiment. They were given no specific instructions about the experiment. They only were given a printed manual in which all the necessary lesson plans could be found.

Pre-test phase. In the pre-test phase the whole classroom was administered a paperand-pencil pre-test. The pre-test examined to what extent the children had already understandings of the controlled comparison strategy. Therefore, each child received a collection of 6 scientific problems, in line with Chen and Klahr (1999), that could be solved. A problem consisted of a comparison of two representations of tests, one pair to a page. Each test involved two 2-level variables and the child was asked to evaluate whether the comparison pair could test the effect of a specific variable. On top of each page a research question was written (e.g., 'what is the effect of the length of the rope on the duration of the swing of a ball?') and at the bottom the child could circle either 'correct experiment' or 'bad experiment depending on his opinion a logic conclusion could be drawn or not. Before starting, the student teacher demonstrated on the basis of one example how a scientific question could be solved. She told the children that first the research question had to be read carefully, that they had to look good to the experiment representations and then that the research question had to be answered. The teacher identified all the variables for that problem and she explained that these variables had two levels and that one of these was a target variable of which the effect had to be tested. No further explanations were given.

The collection of 6 problems were of two types, a confounded and an unconfounded design. Three comparisons varied one single variable (unconfounded design) and 3 
comparisons varied 2 variables at the same time (confounded design) (see Figure 2 for an example).

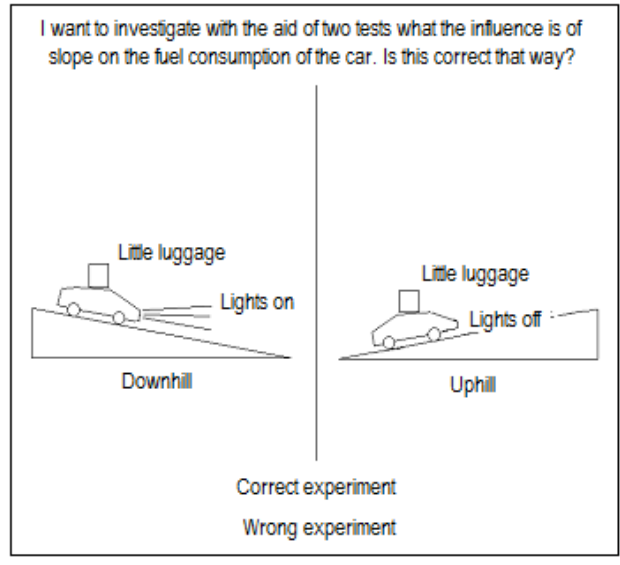

A

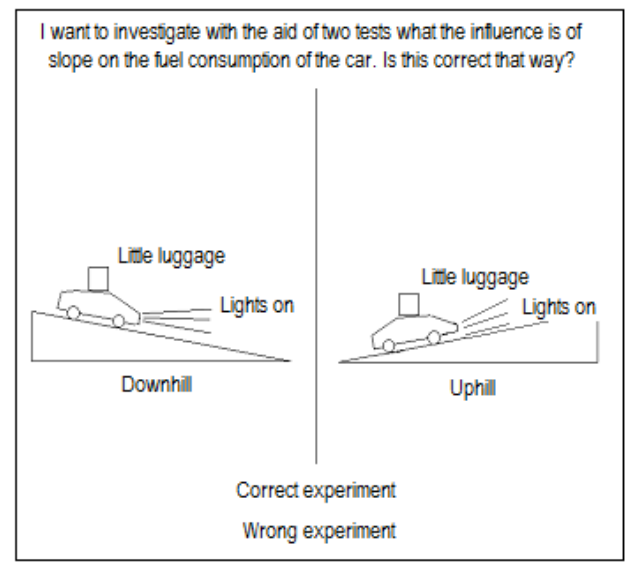

B

Figure 2: Scientific problems in the pre-test (paper-and-pencil) consisted of a comparison of two tests represented side by side. Then, it was asked whether the experiments could test the effect of a specific variable. Figure A represents a confounded design, Figure B represents an unconfounded design.

Instruction phase. Two weeks before the instruction phase started, the student teachers received their lesson contents on paper. The first teacher was told to teach the scientific method starting from 5 scientific problems, this was the CCS-group. The other teacher received exactly the same instructions with the exception that the children were learned to use the scientific thinking circle to solve the 5 scientific problems. This was the CCS+MT-group. The five scientific problems were as follows 1) does a carrot floats better in salt water than tap water?, 2) do large objects sink faster than small objects?, 3) does the speed of sinking of an object depends on the height from where an object is dropped?, 4) does the amount of water being moved depends on the size of an object? and 5) does the height of the water depends on the shape of a recipient? By way of example, the first scientific problem is presented here: does a carrot floats better in salt water than tap water?

Children from the CCS-group were taught how to handle such questions, and how it can be applied. The teacher started with the research question and told that she wanted to know whether a carrot floats better in water when salt is added. Then, the teacher let the children brainstorm and communicate their ideas about the subject and concluded that the amount of salt had to be varied and that it had to be verified what would happen with the carrot when dropped into the water. Then the teacher told the children that two containers with water should be prepared and that in only one of the containers salt should be added. 
While observing the experiment very carefully, it was told then that a piece of carrot should be dropped into the water, first in the one container and then in the other. The experiment was executed by the teacher herself while all the children tooked place around her. Finally, the children were asked to articulate exactly what was measured and they were encouraged to interprete the output of the experiment. For the other tests the same problem solving plan was used. The scientific problems were resolved in one session of 50 minutes.

In the CCS+MT-group, the same scientific questions were presented whith the exception that now the children were learned to solve scientific questions with the aid of the scientific thinking circle. The children of the CCS-MT-group received no additional scientific content. The children only were told that scientific problems always must be resolved in a systematic way and that it consisted of 4 different steps: an orientation phase, an exploration phase, an execution phase and an evaluation phase. The children were told that in each phase a question was accompanied: for phase 1: "What is the problem", for phase 2:"How should I approach the problem?" For phase 3: "I act" and, for phase 4: "Is the result satisfactory?". These four phases were written down on a sheet of paper for each child. Then the teacher started with telling that she wanted to know whether a carrot floats better in water when salt is added. She attended the children to the first question: "what is the problem" and let the children rephrase the research question in their own words. The teachter asked then the childeren to write down the research question in their own words. Then the teacher focussed childrens' attention on the next question: "How should I approach the problem?". The teacher let the children brainstorm and communicate their ideas about the subject and concluded that the amount of salt had to be varied and that it had to be verified what would happen with the carrot when dropped into the water. Then the teacher told the children that two containers with water should be prepared and that in only one of the containers salt should be added. Again the children were asked to write donw in their own words on their sheets how they would handle the problem. While observing the experiment very carefully, it was told then that a piece of carrot should be dropped into the water, first in the one container and then in the other. The experiment was executed by the teacher herself while all the children tooked place around her. As such, the 3rd question (proposition) was put: 'I act' During this phase children were encouraged to write down the findings of the experiment. Once completed the 4th question was formulated: "Is the result satisfactory?" Here, the children were asked to articulate exactly what was measured and whether the result corresponded with the research question of step 1. For the other tests the same problem solving plan was used. The teacher 
repeated the different phases of the scientific thinking circle and asked "which step has to be first when you have to solve a scientific question?", "Where should then the focus of your attention?" "What was the second, third and fourth step?" etc. Each time it was checked whether the students understood what different steps standed for and on what moment they had to be used while solving a scientific problem. As in the CCS-group, the scientific problems were resolved in a session of about 50 minutes.

The C-group skipped the instruction phase.

Post-test phase. The post-test was scored individually by two different experimenters. Therefore each child was taken individually from the classroom and asked to design two unconfounded experiments starting from two scientific experiments. The problems were presented on a sheet of paper and read aloud by the experimenter with the following instructions: For problem one: "Can you demonstrate through an experiment whether the height from which a ball is dropped has an effect on the loudness when it hits a surface? Here, you have a heavy ball and here you have a light one. Further there is a wooden and a metal shelf. You can use all these materials to set up your experiment" and for the second problem: "Can you demonstrate through an experiment whether the size of a ball has an effect on the loudness when it hits a surface? Here, you have a heavy ball and here you have a light one. Further there is a wooden and a metal shelf. You can use all these materials to set up your experiment." The materials for this scientific question were showed in Figure 1. No further instructions were given. The total time needed to solve one problem was measured once the instructions were given until the child said that he was ready. There was no time restriction. When the child indicated that the first problem was resolved, the second problem was given. When the first problem was not correct resolved, the experimenter gave the following feedback: "With this experiment, you can not reveal the effect of .... In the second question try to find out you can design an unconfounded experiment to answer the scientific question”. A score 1 was given when the child could set up an unconfounded experiment in reply to the scientific question. A score 0 was given in all other cases. So, the maximum score was 2 , the minimum score was 0 for this post-test. 


\section{Results}

\section{Pre-test scores}

With the aid of a one-way ANOVA with group (C, CCS, CCS+MT) as an independent variable and the score on the pre-test as a dependent factor, it was investigated whether children of the C-group, CCS-group, and the CCS+MT-group had equal understandings of the controlled comparison strategy. Results revealed no significant differences between the Cgroup, the CCS-group, and the CCS+MT-group for their scores on the pre-test, $F<1, n s$.

\section{Post-test scores}

Experimentation performance of the C-group, the CCS-group, and the CCS+MTgroup were compared by means of a one-way ANOVA with group ( $\mathrm{C}, \mathrm{CCS}, \mathrm{CCS}+\mathrm{MT})$ as the independent variable and the score on the two scientific questions of the posttest as the dependent variable. The analysis showed no significant difference between the C-group, the CCS-group, and the CCS+MT-group for their experimentation skills, $F<1$, ns.

The total time needed to resolve the first and the second scientific question in the C-group, the CCS-group and the CCS+MT-group was analysed by means of two different one-way ANOVA's. The total time needed acted as the dependent variable. Group (C, CCS, CCS+MT) was the independent variable. The analyses revealed no significant differences between the $\mathrm{C}$ group, the CCS-group and the CCS+MT-group for the total time needed, both $F$ 's $<1, n s$. Thus, we didn't found an indication that children who were taught to solve scientific problems with the controlled comparison strategy actually used this strategy in a post-test. In addition, we expected higher scores for scientific problem solving in children who received metacognitive instructions compared to children who didn't receive instructions about the controlled comparison strategy. However, results revealed no benefit for the group that received metacognitive instructions through the scientific thinking circle.

Finally, we hypothesised that children would spent more time to solve the scientific questions when received the scientific thinking circle compared to children who didn't receive any metacognitive instructions. Again, we did not found a significant difference between the Cgroup, the CCS-group and the CCS+MT-group for the total time needed to solve a scientific question. 
Because of the lack of results in Experiment 1 we opted to set up a second experiment with older children. In Experiment 2, Experiment 1 was replicated with the exception that now children of 11 years old were used.

\section{EXPERIMENT 2}

\section{Method}

\section{Participants}

The sample of Experiment 2 existed of 45 children ( 22 boys and 23 girls) of 11 years old (they ranged in age from 10 years 10 months to 11 years 4 months). Participants camed from three different classes from three different schools in the West-Flanders and EastFlanders region in Belgium serving a middle income population. A class was assigned to either the the CCS+MS-group (controlled comparison strategy + metacognitive support, 15 children), the CCS-group (controlled comparison strategy, 15 children) or the C-group (controls, 15 children). Participants were not identified as at risk neither did they perform below grade level. They were all of West European ethnicity. Parents were asked to sign an agreement for participation of their child. Children nor their parents were rewarded for their participation.

\section{Design and Procedure}

The design and procedure were identical of those used in Experiment 1 with the exeption that two other final year student teachers gave the lessons in the CCS+MT-group and the CCS-group . Student teachers guided the paper-and-pencil tests in the pre-test phase for the entire class group. Scores of these tests were used in order to check whether the three groups (CCS+MT, CCS and C) had similar understandings of the controlled comparison strategy. In the instruction phase the student teachers taught the children of the CCS-group the controlled comparison strategy starting from 5 scientific questions. In the CCS+MT-group, children were also taught to use the scientific thinking circle to to solve scientific problems. In contrast to the pre-test, in the post-test phase childrens' experimentation skills were tested by two experimenters. As in Experiment 1, in the post-test children received 2 scientific questions to resolve with different materials available to them. As in Experiment 1, the posttest was executed individually through two experimenters. 


\section{Results}

\section{Pre-test scores}

In order to find out whether children of the C-group, the CCS-group and the CCS+MT-group had similar understandings of the controlled comparison strategy, their scores on the pre-test were analysed with the aid of a one-way ANOVA with group (C, CCS, $\mathrm{CCS}+\mathrm{MT})$ as an independent variable and the scores on the pre-test as a dependent factor. There were no significant differences between the C-group, the CCS-group, and the $\mathrm{CCS}+\mathrm{MT}$-group for their scores on the pre-test, $F<1, n s$.

\section{Post-test scores}

The scores for problem solving were compared by means of a one-way ANOVA with group (C, CCS, CCS+MT) as the independent variable and the scores for problem solving as the dependent variable. The analysis revealed a significant main effect of group (C-group: $M=0.27, S D=0.56$; CCS-group: $M=0.80, S D=0.86$; CCS+MT-group: $M=1.40, S D=0.81), F(2$, $45)=10.70, p<0.001$, partial $n^{2}=0.337$. Further analyses (Tukey HSD) revealed that the difference between the scores for problem solving of the C-group and the CCS-group was not significant although a tendency could be observed $(p<0.09)$. In contrast, the difference between the scores for problem solving of the CCS-group and the CCS+MT-group proved to be significant $(p<0.05)$. The scores for problem solving for the C-group, the CCS-group and the CCS+MT-group are presented in Figure 3.

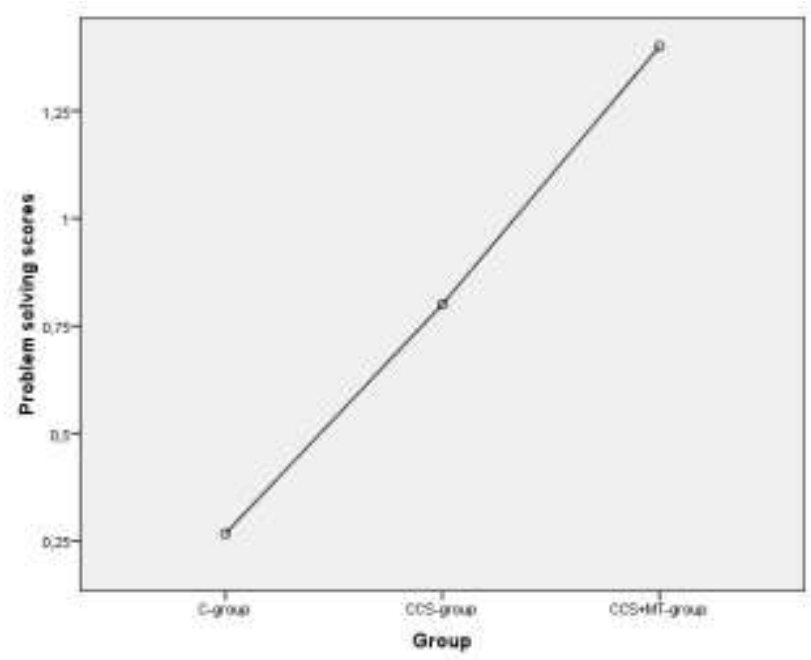

Figure 3: Mean problem solving scores for the C-group, the CCS-group and the CCS+MT-group. 
With another two one-way ANOVA's it was analysed whether children of the Cgroup, the CCS-group and the CCS+MT-group showed a different total time needed to resolve the two scientific questions. The analysis revealed for the first question a significant group effect (C-group: $M=33.60, S D=2.75$; CCS-group: $M=34.00, S D=2.53$; CCS+MTgroup: $M=36.27, S D=2.91), F(2,45)=4.14, p<0.03$, partial $n^{2}=0.165$. Further analysis with Tukey (HSD) revealed that the C-group showed no significantly other times compared to the CCS-group. In contrast, the C-group showed significantly shorter times compared to the CCS+MT-group $(p<0.03)$. The CCS+MT-group did not differ from the CCS-group, although there was a tendency for shorter times in the CCS-group $(p<0.08)$. For the second total time needed a similar pattern of results was found. There was a significant main effect of group (Cgroup: $M=29.60, S D=2.67$; CCS-group: $M=29.20, S D=2.01$; CCS+MT-group: $M=32.60$, $S D=2.90), F(2,45)=7.95, p<0.001$, partial $n^{2}=0.275$. A futher post hoc Tukey test (HSD) showed no signifant difference between the C-group and the CCS-group. In contrast, the Cgroup differed from the CCS+MT-group $(p<0.007)$ and the CCS-group differed significantly from the CCS+MT-group ( $p<0.002)$. Total times needed for the C-group, the CCS-group and the CCS+MT-group of scientific question 1 and 2 are presented in Figure 4 and Figure 5.

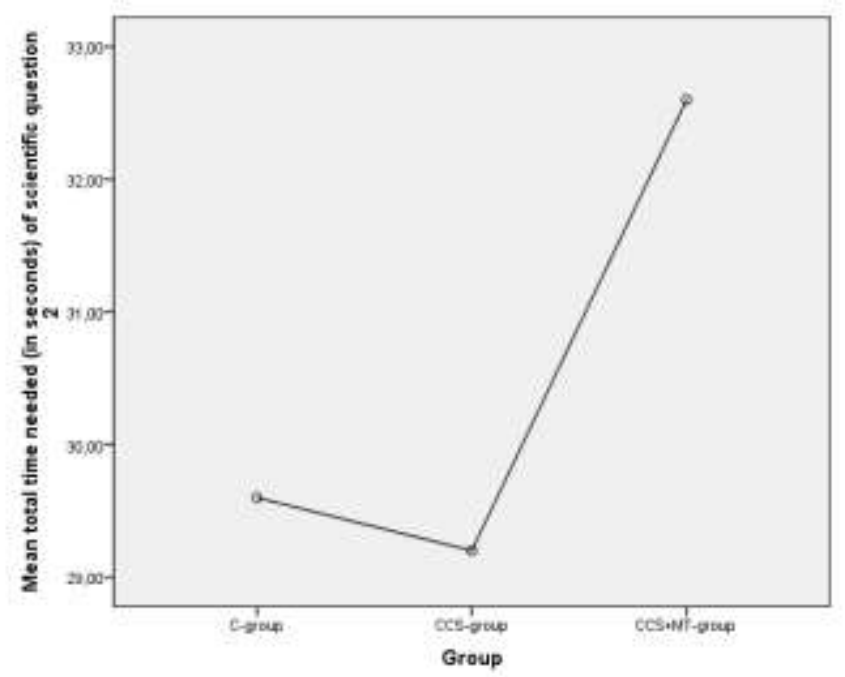

Figure 4: Mean total time needed to solve the first scientific question in the post-test for the C-group, the CCS-group and the CCS+MT-group. 


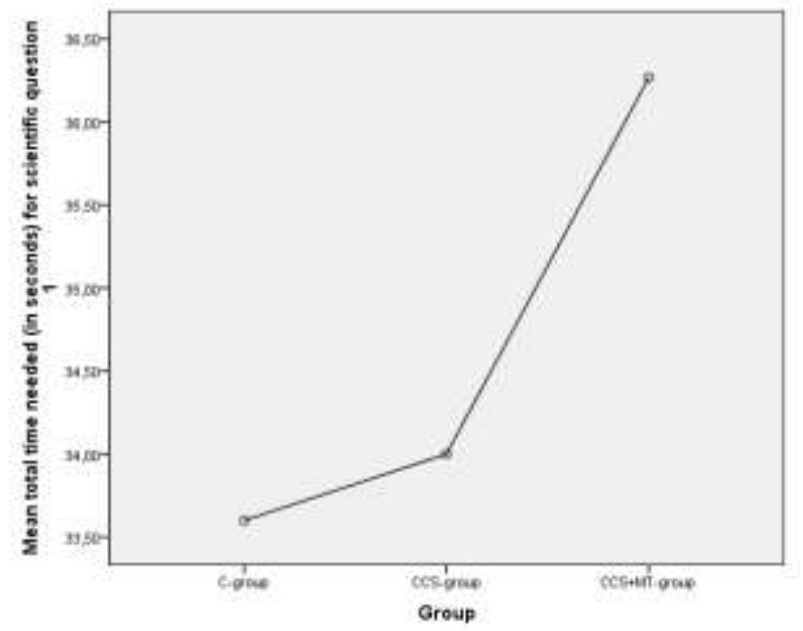

Figure 5: Mean total time needed to solve the second scientific question in the post-test for the Cgroup, the CCS-group and the CCS+MT-group.

Together, it was found that children who learned to solve scientific problems with the aid of the scientific thinking circle were more inclined to spend more time to solve the scientific questions compared to children who did who did not received this metacognitive support. In addition, it was found that children who were taught the controlled comparison strategy were more able to design an unconfounded experiment in the post-test compared to children who did not receive any instructions. Children who also received the metacognitive training performed better than the other groups.

\section{Discussion and Conclusions}

In the present study children of 9 and 11 years old learned in a short lasting program how to design a scientific experiment starting from a scientific question. In order to set up an such an experiment, children were taught the controlled comparison strategy. Learning the controlled comparison strategy involved learning to make a comparison between two instances that differ only on a single property while all other variables were held constant to prevent that they influence the outcome of the analysis (Kuhn, Black, Keselman \& Kaplan, 2000). In such a way the acquisition of the controlled comparison strategy could offer children a strong constraint on search in the space of experiments, contributing to their development of scientific reasoning (Strand-Cary \& Klahr, 2008). 
It was questioned whether children's scientific problem solving could be supported by a metacognitive instructional method. Therefore, children were thaught to design their scientific experiments with the scientific thinking circle (Dejonckheere, Van de Keere, and Mestdagh, 2010). The scientific thinking circle is a step-by-step plan that divides the scientific problem into manageable pieces which children help to regulate their thoughts and actions over time.

We designed a quasi-experiment in which we compared three different groups. A first group was taught to design a simple scientific experiment through the controlled comparison strategy toghether with the scientific thinking circle. A second group was thaught the controlled comparison strategy without metacognitive support. A final group received no specific instructions. Firstly, we expected higher problem solving scores in a hands-on posttest with children who learned to use the controlled comparison strategy for scientific problem solving compared to children who didn't receive such instructions. Secondly, we expected that children who learned to design a scientific experiment with the controlled comparison strategy should obtain better post-test scores when they received metacognitive support throught the scientific thinking circle compared to children who only were taught the control of variables stratey. In line with the second expectation, we also hypothesised that children would take more time to resolve a scientific problem when they received metacognitive instructions indicating their impulsive behaviour was inhibited.

In Experiment 1 children of 9-years old were involved but no signitificant higher posttest scores or different problem solving times were observed a) between children who learned to design a scientific experiment with the controlled comparison strategy and children who received no specific instructions and $b$ ) between children who learned to design a scientific experiment with the scientific thinking circle and children who only reveived the controlled comparison strategy. Experiment 2 replicated Experiment 1 with the exception that 11-yearolds were involved instead of children of 9 years old. For this older age group, the following effects were found. Firstly, it was found that children who were thaught the controlled comparison strategy together with metacognitive support through the scientific thinking circle achieved higher scores in the post-test compared to childeren who learned to make controlled comparisons without metacognitive support and children who didn't receive any instructions at all. Secondly, it was found that children who received the scientific thinking circle spent more time to solve the scientific problems in the post-test compared to the other groups. 
In contrast to Experiment 1, the results of Experiment 2 indicate that learning to design simple scientific experiments is more effective with explicite instruction. This is in agreement with other studies that argue that instruction plays an pivotal role in the acquisition of a variety of core scientific procedures and concepts (e.g., Strand-Cary \& Klahr, 2008). However, helping children to become skilled experimenters is more than telling them how to design a scientific experiment. Offering heuristic support can help problem solvers to reach a certain goal in a complex problem solving situation (Veermans, van Joolingen, \& de Jong, 2006). The present study indicates that children clearly benefit of some metacognitive support that regulates their thoughts and actions over time. Metacognitive instructions may give rise to insight into learner's awareness and executive control of knowledge constructions (Michalsky, Mevarech, \& Haibi, 2009).

Knowing how to regulate his own thoughts and actions is an important skill to learn in primary schools since children usually do not know their own cognitive strengths and weaknesses as well as cognitive self-regulation. For that reason, external regulation by the teacher may compensate for the absence of this knowledge and skills. Children should be introduced into the skill of using metacognitive knowledge to guide the plans they make, the strategies they select, and the interpretations of their performance so that awareness leads to effective problem-solving (Paris \& Winograd, 2001). Such a control of children's thoughts and behavior is in agreement with Bandura's view on self-regulation (Bandura, 1986). The author argues that self-observation, judgment and self-response constitute self-regulation and even self-esteem in the long run. The present study indicates that children of 11 years old can learn to self-regulate their own scientific problem solving when the teacher offers a tool or a structure to learn these behaviors. Of course, the teacher plays an important role in the development of self-regulation, he models components of self-regulation and offers a social context in which children can support one another when practicing copying his behaviors (Joyce \& Hipkins, 2005) that reflect the step-by-step plan of the scientific thinking circle.

Another indication that children benefitted from metacognitive support was that they showed longer problem solving times in the hands-on post-test. Looking at how scientists work offers in many cases information about what skills should need to develop in children. One such thing is that experts in science spent a lot of time in planning, rehearsal and preparation of their activities. In contrast, young children are often externally controlled and start in many cases with experimenting without being aware of a plan. The scientific thinking circle is 
then a way to stop children's impulsiveness at different levels: 1) they are encouraged to phrase, express, repeat, or reformulate the scientific question problem in their own words, 2) children are encouraged to think of different solutions to the problem strenghtening their theoretical position and their representations of the task goal, 3) children are made conscious of seaching a strategy. This proces of searching in the space of experiments was facilitated in children who received instructions about the controlled comparison strategy and 4) children are forced to pay attention to the outcome of the experiment regarding to the problem formulation established in the first step.

A remarkable finding is the lack of findings with 9-year-olds. Indeed, the results of Experiment 1 are in contrast to results of other studies on scientific thinking with elementary school children. For instance Chen and Klahr (1999) and Klahr and Nigam (2004) found that children of 9-year olds were able to understand the controlled comparison strategy after they received a brief intervention of a teacher. One possible reason is that in the present study, the post-test was rather difficult for 9-year-olds since children were asked to design an experiment starting from a rather vague instruction such as can you demonstrate through an experiment whether the size of a ball has an effect on the loudness when it hits a surface? In the study of Chen and Klahr (1999), for example, participants were more directly tested for their understandings of the controlled comparison strategy. The questions the authors then asked referred directly to the use of this strategy (for instance, they asked the participants to make a comparison that could demonstrate whether the length of a spring make a difference in how far it can be stretched). In contrast, in our study, we were interested to what extent children were able to design a scientific experiment starting from a scientific question. This means that they first had to understand the question, then that they had to figure out which variables were included and how the direction of the causal relationship between the variables could be represented. Next they had to generate a hypothesis and to set up the experiment. Such activities entail strong cognitive loads that burden a child's information capacity, especially when the child is young and the task is difficult. One might expect then that metacognitive instructions should strenghten childrens problem solving capacities. However, the results of Experiment 1 do not confirm this hypothesis. Again, a limited informationprocessing capacity is probably the reason for the lack of metacognitive gains. According to Lan and Repman (1998) metacognitive instructions too demand an amount of cognitive capacities which may lead to a pernicious competition between metacognitive instructions and other learning processes. This is in line with the theory of utilisation deficiency in which 
children experience little or no benefit in task performance from the use of a particular strategy (Bjorklund, Miller, Coyle \& Slawinsky, 1997). Ways to overcome such a competition effect are lowering the task difficulty or offering more practicing (so metacognitive actions should become increasingly automatic).

The results of the present study complement those of Dejonckheere, Van de Keere en Mestdagh (2010). In that study a significant improvement for problem solving with the scientific thinking circle was found in physical phenomena in 6-year-olds. In the present study it was demonstrated that teaching the scientific thinking circle is useful for older children as long as the task difficulty is adjusted to the child.

\section{References}

Bandura, A. (1986). Social foundations of thought and action: A social cognitive theory. Englewood Cliffs, NJ: Prentice-Hall.

Bash, M., \& Camp, B. (1975). Think aloud program: group manual. Unpublished manuscript, University of Colorado Medical School.

Beishuizen, J., Wilhelm, P., \& Schimmel, M. (2004). Computer-supported inquiry learning: effects of training and practice. Computers \& Education, 42, 389-402.

Bjorklund, D.F., Miller, P.H., Coyle, P.R., \& Slawinsky, J.L. (1997). Instructing children to use memory strategies: evidence of utilization decifiencies in memory training studies. Developmental Review, 17, 4, 411-441.

Borkowski, J., Carr, M., \& Pressely, M. (1987). "Spontaneous" strategy use: Perspectives from metacognitive theory. Intelligence, 11, 61-75.

Carey, S. (1985). Conceptual change in childhood. Cambridge, MA: MIT Press.

Chen, Z., \& Klahr, D. (1999). All other things being equal: children's acquisition of the control of variables strategy. Child Development, 70, 1098-1120.

Dejonckheere, P.J.N., Van de Keere, K., \& Mestdagh, N. (2010). Training the scientific thinking circle in pre- and primary school children. Journal of Educational Research, 103, 1-16.

Desoete, A. (2007). Evaluating and improving the mathematics teaching-learning process through metacognition. Electronic Journal of Research in Educational Psychology, 5(3), 705-730. 
Dunbar, K. \& Klahr, D (1989). Developmental differences in scientific discovery processes. In Simon, H.A., Klahr, D., \& Kotovsky, K. (Eds.). Complex information processing: the impact of Herbert A. Simon (pp. 109-143). Lawrence Erlbaum: New Jersey.

Eshach, H. \& Fried, M.N. (2005). Should Science be Taught in Early Childhood? Journal of Science Education and Technology, 14, 3, 315-336.

Eysenck, M.W., \& Keane, M.T. (2005). Cognitive Psychology. Cognitive Psychology Press: East Sussex.

Feist, G.J. (2006). The psychology of science and the origins of the scientific mind. New Ha ven, CT: Yale University Press.

Geary, D.C. (2007). Educating the evolved mind: conceptual foundations for an evolutional psychology. In J.S. Carlson \& J.R. Levin (Eds.), Educating the evolved mind: conceptual foundations for an evolutionary educational psychology (pp. 1-99). Charlotte, NC: Information Age.

Hofstein, A., Kipnis, M., \& Kind, P. (2008). Learning in and from science laboratories: enhancing students' metacognition and argumentation skills. In Calvin, L., \& Petroselli, L. (Eds.), Science education: Issues and developments (pp. 59-94). Nova Science Publishers: New York.

Holyoak, K.J., \& Morrison, R.G. (2005). The Cambridge handbook of Thinking and reasoning. Cambridge University Press: New York.

Inhelder, B. \& Piaget, J. (1958). The Growth of Logical Thinking from Childhood to Adolescence. Basic Books, New York, NY.

Joyce, C., \& Hipkins, R. (2005. I know something about forces. Self-regulated learning during science investigations in a junior classroom. Research Information for Teachers, 2, 38-42.

Kamann, M.P., \& Wong, B.Y. (1993). Inducing adaptive coping self-statements in children with learning disabilities through self-instruction training. Journal of Learning Disabilities, 26, 630-638.

Klahr, D. (2005). A framework for cognitive studies of science and technology. In Gorman, M.E., Tweney, R.D., Gooding, D.C., \& Kincannon, A.P. (Eds.) Scientific and technological thinking (pp. 81-96). Lawrence Erlbaum: New Jersey.

Klahr, D. (2000). Exploring science: The cognition and development of discovery processes. Cambridge, MA: MIT Press.

Klahr, D., \& Dunbar, K. (1988). Dual space search during scientific reasoning. Cognitive Science, 12, 1, 1-48. 
Klahr, D., \& Nigam, M. (2004). The equivalence of learning paths in early science instruction: effects of direct instruction and discovery learning, Psychological Science $15,10,661-667$.

Kuhn, D., Black, J., Keselman, A., \& Kaplan, D. (2000). The development of cognitive skills to support inquiry learning. Cognition and Instruction, 18, 4, 495-523.

Lan, W., \& Repman, J. (1998). Effects of practicing self-monitoring of mathematical problem solving heuristics on impulsive reflective college students' heuristics knowledge and problem solving ability. Journal of Experimental Education, 67, 32-53.

Michalski, T., Mevarech, Z.R., \& Haibi, L. (2009). Elementary school children reading scientific texts: Effects of metacognitive instruction. Journal of Educational Research, 102, 363-376.

Meichenbaum, D. (1990). Cognitive perspective on teaching self-regulation. American journal on mental retardation 94, 4, 367-369.

Newell, A., \& Simon H.A. (1972). Human problem solving. Englewood Cliffs, NJ: Prentice Hall.

Paris, S.G., \& Winograd, P. (2001). The role of self-regulated learning in contextual teaching: Principles and practices for teacher preparation. Available on the Internet at: http://www.ciera.org/library/archive/2001-04/0104parwin.htm.

Pearson, P.D. \& Dole, J.A. (1987). Explicit comprehension instruction: a review of research and a new conceptualization of learning. Elementary School Journal, 88, 151-165.

Pearson, P.D., \& Fielding, L. (1991). Comprehension instruction. In R. Barr, M.L. Kamil, P.B. Mosenthal, \& P.D. Pearson (Eds.), Handbook of reading research: Volume II (pp. 815-860). White Plains, NY: Longman.

Pressley, M., Johnson, C.J., Symons, S., McGoldrick, J.A., \& Kurita, J.A. (1989). Strategies that improve children's memory and comprehension of text. Elementary School Journal, 90, 3-32.

Palincsar, A.S., \& Brown, A.L. (1984). Reciprocal teaching of comprehension- fostering and monitoring activities. Cognition and Instruction, 1, 117-175.

Pressley, M. (1998). Reading instruction that works: The case for balanced teaching. New York: Guilford Press.

Reynolds, W. M., \& Miller, G. E. (2003). Current perspectives in educational psychology. In I. B. Weiner (Series Ed.) \& W. M. Reynolds \& G. E. Miller (Vol. Eds.). Handbook of psychology: Volume 7. Educational psychology (pp 3-20). New York: John Wiley \& Sons. 
Strand-Cary, M., \& Klahr, D. (2008). Developing elementary science skills: Instructional effectiveness and path independence. Cognitive Development, 23, 488-511.

Teong, S.K. (2003). The effect of metacognitive training on mathematical word-problem solving. Journal of Computer Assisted Learning, 19, 46-55.

Thurston, A., Grant, G., \& Topping, K.J. (2006). Constructing understanding in primary science: An exploration of process and outcomes in the topic areas of light and the earth in space. Electronic Journal of Research in Educational Psychology, 4(1), 1-34.

Veermans, K.H., Van Joolingen, W.R., \& de Jong, T. (2006). Use of Heuristics to Facilitate Scientific Discovery Learning in a Simulation Learning Environment in a Physics Domain. International Journal of Science Education, 28, 341-361.

White, B.Y., \& Frederiksen, J.R. (1998). Inquiry, modeling, and metacognition: making science accessible to all students. Cognition and instruction, 16, 1, 3-118.

Wilhelm, P., Beishuizen, J.J., \& Van Rijn, H. (2004). Studying inquiry learning with FILE. Computers in Human Behavior, 21, 933-943.

Zion, M., Michalsky, T., \& Mevarech, Z.R. (2005). The effects of metacognitive instruction embedded within an asynchronous learning network on scientific inquiry skills. International Journal of Science Education, 27, 957-983. 